\title{
Terabit/s serial optical communications
}

\section{[invited]}

Oxenløwe, Leif Katsuo; Galili, Michael; Mulvad, Hans Christian Hansen; Clausen, Anders; Jeppesen, Palle

\section{Published in:}

Proceedings of Annual Meeting of the IEEE Photonics Society 2009

Link to article, DOI:

10.1109/LEOS.2009.5343174

Publication date:

2009

Document Version

Publisher's PDF, also known as Version of record

Link back to DTU Orbit

Citation (APA):

Oxenløwe, L. K., Galili, M., Mulvad, H. C. H., Clausen, A., \& Jeppesen, P. (2009). Terabit/s serial optical communications: [invited]. In Proceedings of Annual Meeting of the IEEE Photonics Society 2009 (pp. WQ1). IEEE. https://doi.org/10.1109/LEOS.2009.5343174

\section{General rights}

Copyright and moral rights for the publications made accessible in the public portal are retained by the authors and/or other copyright owners and it is a condition of accessing publications that users recognise and abide by the legal requirements associated with these rights.

- Users may download and print one copy of any publication from the public portal for the purpose of private study or research.

- You may not further distribute the material or use it for any profit-making activity or commercial gain

- You may freely distribute the URL identifying the publication in the public portal 


\title{
Terabit/s serial optical communications (invited)
}

\author{
L.K. Oxenløwe, M. Galili, H.C. Hansen Mulvad, A.T. Clausen and P. Jeppesen \\ DTU Fotonik, Department of Photonics Engineering, Technical University of Denmark, \\ Building 343, DK-2800, Kgs. Lyngby, Denmark, lkox@fotonik.dtu.dk
}

\begin{abstract}
We report on an experimental demonstration of a 1.28 Tbit/s serial data generation and demultiplexing and discuss the prospects of upgrading other essential functionalities to 1.28 Tbit/s.
\end{abstract}

\section{INTRODUCTION}

In year 2000, the first demonstration of reaching Tbit/s data rates on a single wavelength channel was achieved [1] using 640 Gbaud pol-MUX and simple OOK. Since then, only very few attempts have been made to approach this outstanding feat. Recently it has become apparent that Tbit/s bit rates for Ethernet applications will be needed very soon [2] and that the overall necessary capacity per fiber will reach several tens of Tbit/s [3], while the need for power reductions is getting more and more evident, where the Internet today emits more than $2 \%$ of the global $\mathrm{CO}_{2}$ emission. This has spurred on a regained focus on increasing the bit rates, both with a single-channel perspective and with a spectral efficiency perspective using advanced modulation formats and latest advances in coherent receiver technology. A high single-channel bit rate has generally had the effect of cutting the overall systems cost, due to reduced network complexity, fewer components and hence lower power consumption per bit. A high spectral efficiency may also help in power per bit since the bandwidth is more efficiently used. Using OFDM has a high component count in the terminals, but on the other hand is very resilient to transmission impairments and hence needs less inline equipment for e.g. regeneration. So the optimum path to energy efficient high bandwidth communication systems is still open, and all routes must be explored to ensure future sustainability.

Recent highlights of the endeavors to boost the bit rates to the Tbit/s regime include the record breaking $2.56 \mathrm{Tbit} / \mathrm{s}$ using DQPSK and pol-MUX on a 640 Gbaud RZ pulse rate [4] and a recent upgrade to 8PSK on 640 Gbaud with pol-MUX resulted in below FEC-limit $3.56 \mathrm{Tbit} / \mathrm{s}$ using coherent reception and $2.38 \mathrm{Tbit} / \mathrm{s}$ using 16 QAM on 640 Gbaud without pol-MUX [5]. The combination of time division multiplexing and coherent receiver techniques has also been successfully studied by the Kikuchi group and recently led to a $1.28 \mathrm{Tbit} / \mathrm{s}$ based on 16 QAM on a 160 Gbaud pol-MUX OTDM pulse train [6]. Using coherent OFDM has also recently been demonstrated to reach $1 \mathrm{Tbit} / \mathrm{s}$ [7] and even $1.2 \mathrm{Tbit} / \mathrm{s}$ [8]. The simple OOK purely serial format has the advantage of being simple and having a low component count as well as being the only format with well-established suggestions for all-optical regeneration, which may also aid in driving the power consumption down. Drawbacks are the relatively low spectral efficiency and the severe challenges with respect to long-haul transmission. Until very recently, the baud rate had been limited to $640 \mathrm{Gbaud}$, but a new record of $1.28 \mathrm{Tbit} / \mathrm{s}$ was recently demonstrated [9] using only optical time division multiplexing (OTDM) from 10 $\mathrm{Gbit} / \mathrm{s}$ and remaining in one single polarization.

In this paper we describe our recent progress on $1.28 \mathrm{Tbit} / \mathrm{s}$ data generation and demultiplexing and discuss opportunities and limitations of this technology. In addition we describe the demonstrated essential functionalities at $640 \mathrm{Gbit} / \mathrm{s}$ and discuss the prospect of upgrading these to $1.28 \mathrm{Tbit} / \mathrm{s}$, and also what impact this could have on designing new network scenarios.

\section{EXPERIMENTAL DEMONSTRATIONS}

A schematic of the experimental set-up used for the demonstrations described here is shown in Figure 1. An erbium glass oscillator pulse generating laser (ERGO-PGL) supplies a $10 \mathrm{GHz}$ optical pulse train at $1557 \mathrm{~nm}$ having a pulse width of 1.3 ps. A Mach-Zender modulator (MOD) is used to encode a data sequence $\left(2^{7}-1\right.$ PRBS $)$ on the pulse train. The $10 \mathrm{~Gb} / \mathrm{s}$ modulated pulse train is compressed down to $350 \mathrm{fs}$ in a highly

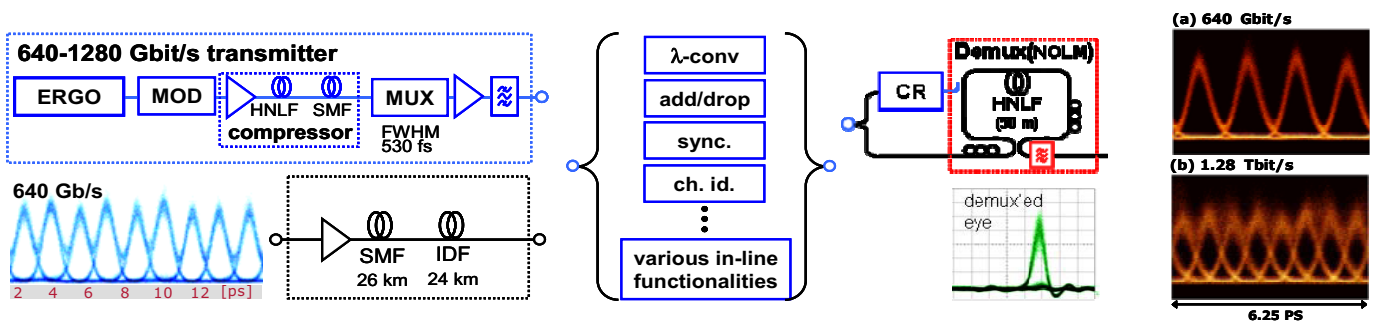

Figure 1. Schematic of the DTU OTDM test-bed for generating 640-1280 Gbit/s data. Insets: a) $640 \mathrm{Gbit} / \mathrm{s}$ eye diagram, b) $1.28 \mathrm{Tbit} / \mathrm{s}$ eye diagram. 
non-linear fiber (HNLF) SPM-based chirp unit followed by linear dispersion, and subsequently multiplexed to 160-320640-1280 Gbit/s in a passive fibre delay PRBS and polarization maintaining multiplexer (MUX). The multiplexed data is then subjected to various experiments.

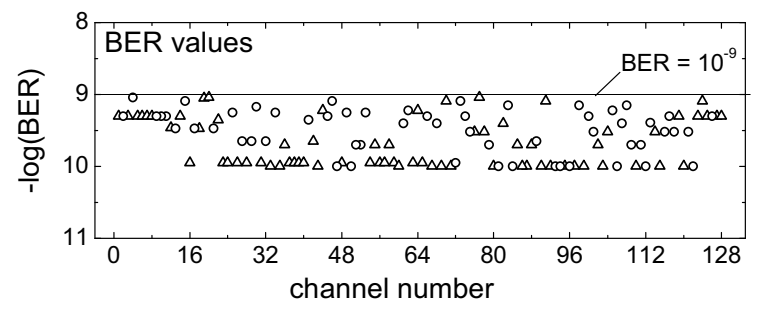

Figure 2. BER values for all 128 tributaries. All channels are error free $\left(\mathrm{BER}<10^{-9}\right)$ corroborating the open eyes from figure 1. Taken from [9].

Figure 2 shows the BER results for all 128 demultiplexed OTDM tributaries of the $1.28 \mathrm{Tbit} / \mathrm{s}$ data signal. For this experiment a $15 \mathrm{~m}$ long HNLF $\left(\gamma \sim 10.5 \mathrm{~W}^{-1} \mathrm{~km}^{-1}\right.$, zero dispersion at $1545 \mathrm{~nm}$ and a flat dispersion profile (slope: $0.015 \mathrm{ps} / \mathrm{nm}^{2} \mathrm{~km}$ )) was used in a NOLM for the demultiplexing So, $1.28 \mathrm{Tbit} / \mathrm{s}$ serial data multiplexing and demultiplexing is possible as longs as the compressed pulses are of sufficient high quality and the walk-off is small in the NOLM.

Other interesting functionalities have already been demonstrated at $640 \mathrm{Gbit} / \mathrm{s}$ and show promise for higher bit rates. This goes for transmission and clock recovery, wavelength conversion and add/drop multiplexing, all of which has been demonstrated at $640 \mathrm{Gbit} / \mathrm{s}$ in our test-bed [10-15]. These functionalities are likely to be possible to perform at $1.28 \mathrm{Tbit} / \mathrm{s}$, as the physical properties involved in the signal processing are fast enough. For the clock recovery scheme described in [10-11], a periodically poled Lithium Niobate (PPLN) device was used as an all-optical mixer, and it was fast enough to resolve the $640 \mathrm{Gbit} / \mathrm{s}$ data signal. In [16] is described how a similar PPLN device is used to compress an optical pulse to less than $100 \mathrm{fs}$, revealing the great speed potential of the $\chi^{(2)}$ process, which takes place on a fs timescale. So these devices have great potential for Tbit/s applications. The HNLF used for wavelength conversion and add/drop multiplexing in [12-15] are the same types as used for the $1.28 \mathrm{Tbit} / \mathrm{s}$ experiment, so they have already proven themselves able to operate at Tbit/s speeds. An alternative to HNLF is the very non-linear chalcogenide waveguides. In [17] we showed that such a device could be used to demultiplex a $640 \mathrm{Gbit} / \mathrm{s}$ data signal, and as with the HNLF and the PPLN, the active effect used for the optical signal processing is ultrafast, and the only speed limitation lies in the design of the dispersion (this goes for all the devices). Recently, in [18], it was shown that these waveguides indeed have a $\mathrm{THz}$ response with a modulation bandwidth on the order of $2.5 \mathrm{THz}$. This means that this technology would also lend itself favorably to Tbit/s serial communication systems.

\section{CONCLUSION}

We have described a $1.28 \mathrm{Tbit} / \mathrm{s}$ experimental demonstration and shown that there are several technologies that can potentially deal with such high bit rates. This means that Tbit/s serial optical data may be a feasible path to accommodate for the future need for high-capacity communication systems.

\section{ACKNOWLEDGMENT}

This work is partly funded by the Danish Research Council project NANO-COM. OFS Fitel Denmark Aps is acknowledged for providing HNLF, CUDOS Australia for chalcogenide waveguides and NIMS Japan for PPLNs.

\section{REFERENCES}

[1] M. Nakazawa et al, "1.28 Tbit/s-70 km OTDM transmission using thirdand fourth-order simultaneous dispersion compensation with a phase modulator", Electron. Lett., 36 (24), (2000), pp 2027-2029

[2] Bob Metcalfe, http://www.ofenfoec.org/conference program/Plenary.aspx

[3] Emmanuel B. Desurvire, "Capacity Demand and Technology Challenges for Lightwave Systems in the Next Two Decades", J. Lightwave Technol., Vol. 24, No. 12, December 2006 (invited paper)

[4] H.G. Weber et al, "Single channel $1.28 \mathrm{Tbit} / \mathrm{s}$ and $2.56 \mathrm{Tbit} / \mathrm{s}$ DQPSK transmission", Electron.Lett., 42 (3), (2006), pp 67-68

[5] C. Schmidt-Langhorst et al, "Generation and coherent time-division demultiplexing of up to $5.1 \mathrm{~Tb} / \mathrm{s}$ single-channel 8-PSK and 16-QAM signals", OFC 2009, post-deadline paper PDPC6.

[6] C. Zhang et al, "Demodulation of $1.28 \mathrm{Tbit} / \mathrm{s}$ polarization-multiplexed 16-QAM signals on a single carrier with digital coherent receiver", OFC 2009, paper OTuG3.

[7] Y. Ma et al, "1 Tb/s per channel coherent optical OFDM transmission with subwavelength bandwidth access", OFC 2009, PD paper PDPC1.

[8] R. Dischler et al, "Transmission of $1.2 \mathrm{Tbit} / \mathrm{s}$ continuous waveband PDM-OFDM-FDM signal with spectral efficiency of $3.3 \mathrm{bit} / \mathrm{s} / \mathrm{Hz}$ over $400 \mathrm{~km}$ of SSMF", OFC 2009, post-deadline paper PDPC2.

[9] H.C. Hansen Mulvad et al, "1.28 Tbit/s single-polarisation serial OOK optical data generation and demultiplexing", Electron. Lett. (2009) Vol. 45 No. 5 p. $280-281$

[10] L.K. Oxenløwe et al, "640 Gbit/s data transmission and clock recovery using an ultrafast periodically poled Lithium Niobate device”, IEEE J. Lightwave Technol., vol. 27, no. 3 pp. 205-213 (2009).

[11] L.K. Oxenløwe et al, " $640 \mathrm{Gbit} / \mathrm{s}$ clock recovery using periodically poled Lithium Niobate", Electron. Lett. 44 (5), (2008), pp. 370

[12] M. Galili et al,"Optical wavelength conversion by cross-phase modulation of data signals up to $640 \mathrm{~Gb} / \mathrm{s}$." IEEE Journal of Selected Topics in Quantum Electronics, vol. 14, no. 3, pp. 573-579, May 2008.

[13] M. Galili et al, "640 Gbit/s Optical Wavelength Conversion using FWM in a Polarisation Maintaining HNLF", ECOC'08, paper Tu.3.D.5

[14] H. C. Hansen Mulvad et al, "640 Gbit/s Optical Time-Division Add-Drop Multiplexing in a Non-Linear Optical Loop Mirror", IEEE Lasers and Electro-Optics Society Winter Topical Meeting, Innsbruck, Austria, January 2009. Paper MC4.4.

[15] H. C. Hansen Mulvad et al, "640 Gbit/s Time-Division Add-Drop Multiplexing using a Non-Linear Polarisation-Rotating Fibre Loop", ECOC 2008, paper Tu.3.D.6

[16] S. Ashihara et al, "Optical pulse compression using cascaded quadratic nonlinearities in periodically poled lithium niobate", Applied Physics Letters, Vol. 84, No. 7, (2004), pp 1055-1057

[17] M. Galili et al, "Breakthrough switching speed with an alloptical chalcogenide glass chip: $640 \mathrm{Gbit} / \mathrm{s}$ demultiplexing”, Optics Express, vol. 17, no. 4, pp. 2182-2187, February 2009.

[18] M. Pelusi et al, "Photonic-chip-based radio-frequency spectrum analyser with terahertz bandwidth ",Nature Photonics, Issue Vol.3 Issue.3, Page no. 139-144, 2009 